\title{
Atypical Presentation of a Rare Eyelid Tumor: A Case Report
}

\author{
Speranta Schmitzer ${ }^{1,2 *}$, V Potop ${ }^{1}$, MY Levy ${ }^{3}$ and Ioana Claudia Popteanu ${ }^{1}$ \\ ${ }^{1}$ Emergency Eye Hospital, Bucharest, Romania \\ ${ }^{2}$ Oftalmestet Clinic, Bucharest, Romania \\ ${ }^{3}$ Timioara, Romania
}

*Corresponding author: Speranta Schmitzer, Emergency Eye Hospital, Oftalmestet Clinic, Bucharest, Romania, E-mail: speranta.sch@gmail.com

Received: 13 Jul, 2018 | Accepted: 06 Aug, 2018 | Published: 13 Aug, 2018

Citation: Schmitzer S, Potop V, Levy MY, Popteanu IC (2018) Atypical Presentation of a Rare Eyelid Tumor: A Case Report. J Ophthalmic Stud 1(1): dx.doi.org/10.16966/2639-152X.112

Copyright: (c) 2018 Schmitzer S, et al. This is an open-access article distributed under the terms of the Creative Commons Attribution License, which permits unrestricted use, distribution, and reproduction in any medium, provided the original author and source are credited.

\section{Abstract}

Superficial Angiomyxomas (SA) are a group of uncommon soft tissue, myxoid mesenchymal tumours, found especially on the trunk. They mostly occur in people between 40 and 60 years of age and affect both men and women, in equal measure. The eyelid is an uncommon site of SA. Only two more cases have been reported in the past. We present a case of Superficial Angiomyxoma of the eyelid in an adult male patient.

\section{Introduction}

Superficial Angiomyxomas (SA) are a group of uncommon soft tissue, myxoid mesenchymal tumours, found especially on the trunk [1-3]. They mostly occur in people between 40 and 60 years of age and affect equally men and women [4]. The eyelid is an uncommon site of SA [5,2]. Only two more cases have been reported in the past. We present a case of Superficial Angiomyxoma of the eyelid in an adult male patient.

\section{Case Report}

A 39-year-old male presented with edema in the right upper eyelid (Figure 1), with no cutaneous lesions, which appeared the year prior to the hospital presentation and did not respond to cortisone therapy. He had no personal or family history of ophthalmic disorders, skin tumours or other types of cancer.

The MRI scan (Figure 2) revealed a heterogeneous tumoural mass located in the superior temporal quadrant of the orbit, that was not separated from the lacrimal gland. The preoperative diagnosis, based on the clinical findings and the MRI examination, was that of lacrimal gland tumour.

Incisional biopsy was performed (Figure 3), under local anaesthetic, in order to get a sample for the histological diagnosis. Intraoperative, when the orbital septum was incised, through the incision herniated a well circumscribed, nonencapsulated, red-pinkish mass, $1 \times 0.5 \mathrm{~cm}$ in size, of mucinous consistency unseparated from the palpebral lobe of the lacrimal gland.

The first histological diagnosis was that of a Lymphangioma with the further recommendation of immunohistochemical tests to confirm it. The microscope slides (Figure 4) were reexamined and revealed a lesion comprising of spindle-shaped cells, distributed in a prominent myxoid matrix, with numerous thin-walled blood vessels. The immunohistochemical (Figure 5) analysis showed CD 34 intense positive cells and negative CD 31, EMA, D2-40, S100, MITF, SMA, GFAP, CD10, resulting in a final diagnosis of Superficial angiomyxoma.

After the final diagnosis was made, the patient underwent a new surgical intervention in order to complete the excision of the tumour. The post-operative evolution was good and the patient remained tumour free for approximately one year after surgery when he developed right upper eyelid edema. The consult revealed the reccurence of the tumour and a new surgical intervention was scheduled. Intraoperative, the tumour invaded the orbital lobe of the lacrimal gland, but we managed to perform a complete excision (Figure 6).

\section{Discussion and Conclusion}

Superficial Angiomyxomas are rare, benign myxoid tumours, described for the first time by Allen et al. [1]. The word "superficial" was used in order to distinguish them from aggressive angiomyxomas which are highly locally aggressive tumours occurring preferentially in the female genital region $[6,7]$.

Superficial Angiomyxomas are usually located on the trunk, lower limbs, head, neck or the genitals (penis and vagina) $[2,3,6,8]$. The present case, hence, is unusual, because the eyelid is a highly uncommon site for it's occurrence [2,5,9] .

The diagnosis is histological-characteristic features include extensive myxoid change with spindle or stellate shaped stromal cells that show no nuclear atypia or hyperchromasia. The presence of neutrophils is a diagnostic clue, as these are not present in other superficial myxoid lesions, such as digital myxoma or nerve sheath myxomas $[3,8,10]$.

The treatment is surgical, total excision being curative $[8,11,12]$. This type of tumours do not metastasize, but local recurrence is possible (30\%-40\%), due to their infiltrative growth and the difficulties of a complete excision $[5,8,10,12]$. 


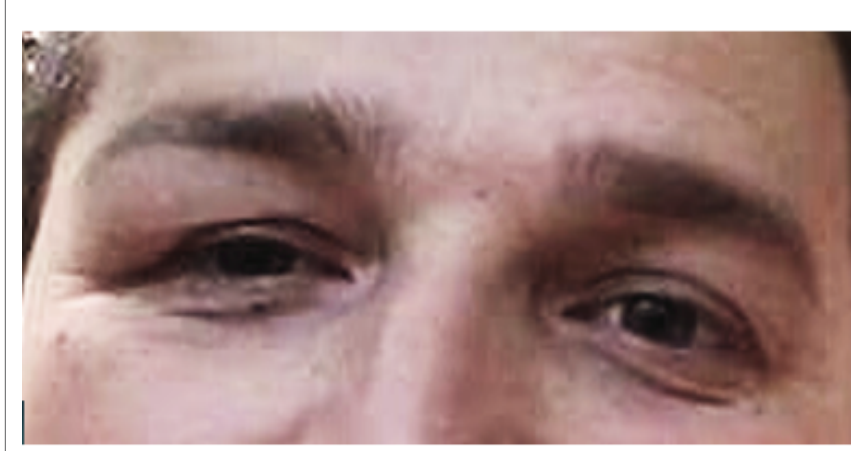

Figure 1: Patient presenting right upper eyelid edema.
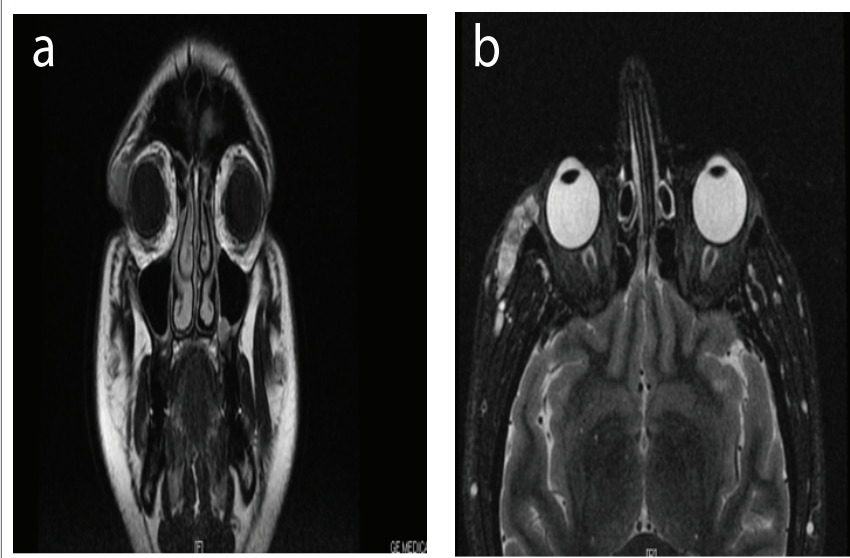

Figure 2: MRI scan revealing a tumoural mass located in the superior temporal quadrant of the orbit.

a) Coronal view

b) Axial view

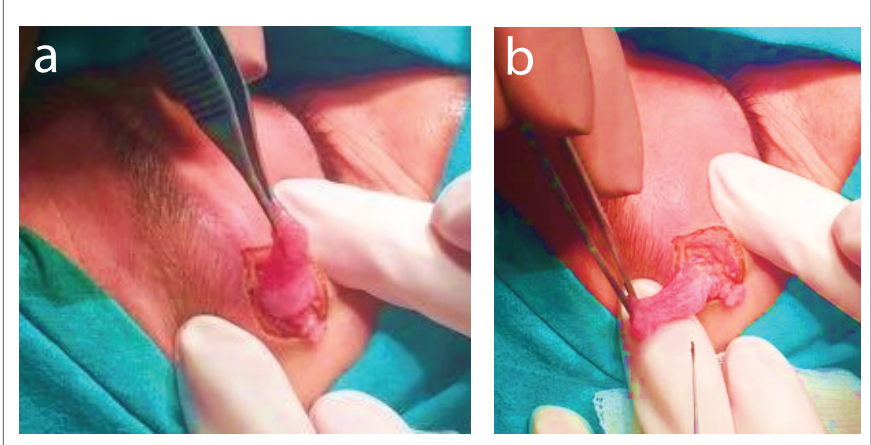

Figure $3(\mathbf{a}, \mathbf{b})$ : Intraoperative aspect of the tumour.

\section{Particularities of this Case}

Atypical clinical presentation-no cutaneous lesions

Localization - only two more cases of superficial angiomyxoma in the eyelid are reported in the literature

First case of superficial angiomyxoma encountered by us in over 20 years of ophthalmic practice

First case of superficial angiomyxoma published by romanian ophthalmologists

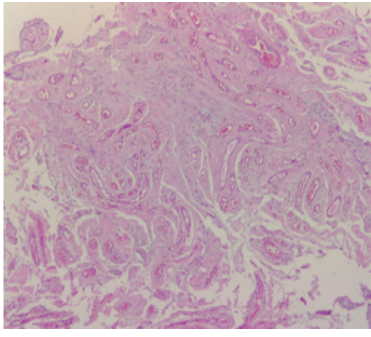

a

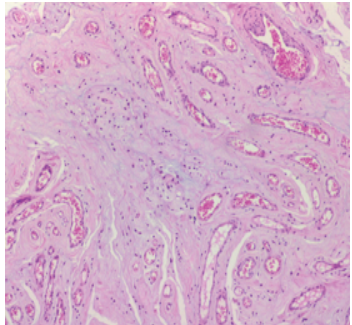

b

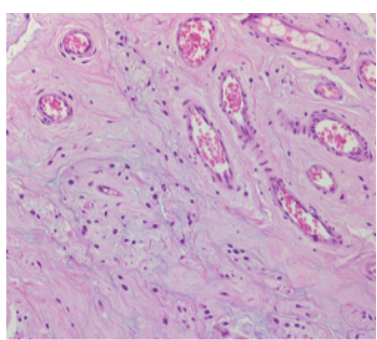

C

Figure 4: Histological appearance of the tumour - a) H\&E magnification $5 x$, b) H\&E magnification $10 x$ and c) H\&E magnification 20x.

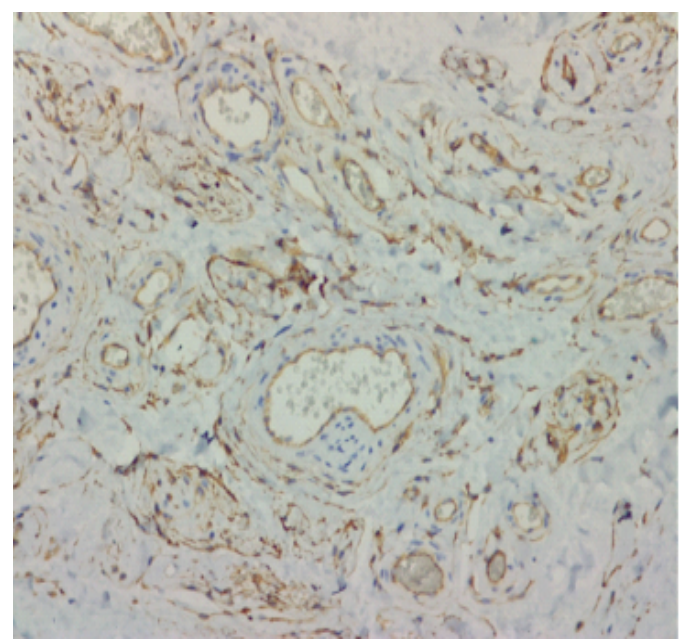

Figure 5: Immunohistochemical analysis - CD 34 intense positive cells.

\section{Conflict of Interest}

The authors declare no conflict of interest.

\section{Patient consent}

Obtained.

\section{Ethics approval}

All procedures performed in our case involving the human participant were in accordance with the ethical standards of the institutional and national research committee and with the 1964 Helsinki Declaration and its later amendments or comparable ethical standards. Informed consent was obtained from the participant included in the study, which is retrospective. 


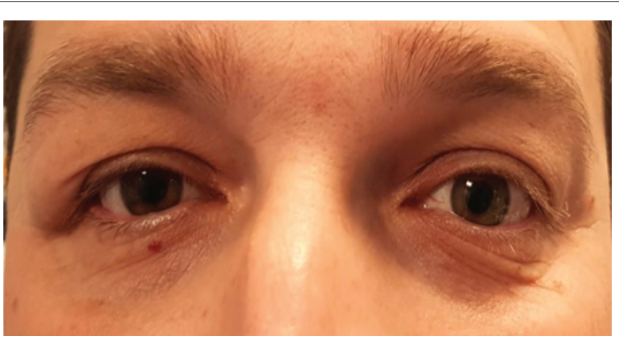

a

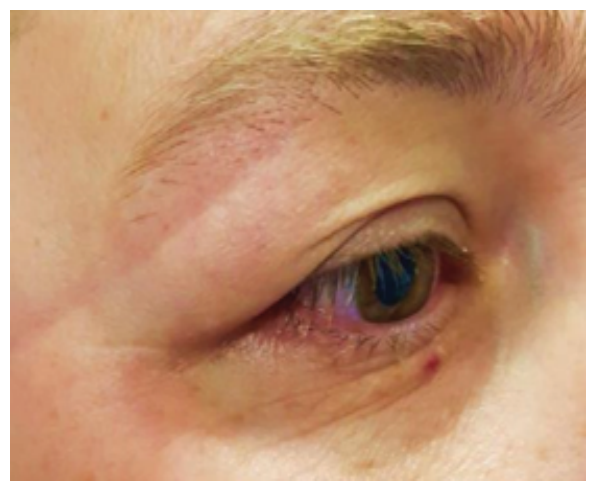

b

Figure $6(a, b)$ : One year after the first surgery - right orbital tumour accompanied by upper eyelid edema.

\section{References}

1. Allen PW, Dymock RB, MacCormack LB (1998) Superficial angiomyxomas with and without epithelial components. Report of 30 tumours in 28 patients. Am J Surg Pathol 12: 519-30.
2. Ali, Naser, Child CS, Michaelides M, Olver JM (2011) Recurrence of a Rare Skin Tumour: Superficial Angiomyxoma in the Eyelid. Can J Ophthalmol 46: 205-206.

3. Diniz, Gulden, Temır G, Ortaç R (2012) Angiomyxoma: Always Myxoid, Sometimes Aggressive. Turk Patoloji Derg 28: 162-164.

4. Satter EK (2009) Solitary Superficial Angiomyxoma: an Infrequent but Distinct Soft Tissue Tumor. J Cutan Pathol 36: 56-59.

5. Yuen HK, Cheuk W, Luk FO, Wat CS, Auyeung K, et al. (2005). Solitary Superficial Angiomyxoma in the Eyelid. Am J Ophthalmol 139: 11411142.

6. Fetsch JF, Laskin WB, Tavassoli FA (1997) Superficial angiomyxoma (cutaneous myxoma): a clinicopathologic study of 17 cases arising in the genital region. Int J Gynaecol Pathol 16: 325-334.

7. Shanmugasundaram, Gouthaman, and Sivasundari Maharajan (2016) Rare Case of Aggressive Angiomyxoma of the Vulva: A Case Report. Cancer and Clinical Oncology 6: 8.

8. Rodríguez-Vázquez M, M García-Arpa, M Delgado, P Cortina, E Vera, G. Romero (2005) Superficial Angiomyxoma. Actas Dermosifiliograficas. U.S. National Library of Medicine.

9. Bolcs S, Juhos P (1975) A caseof palpebral myxoma. Ophthalmologica 171: 488-492.

10. Calone E, Guerin D, McCormick D, Fletcher CD (1999) Superficial angiomyxoma: clinicopathologic analysis of a series of distinctive but poorly recognized cutaneous tumours with tendency for recurrence. Am J Surg Pathol 23: 910-917.

11. Anehosur, Adirajaiah S, Ghosh R (2016) Intraoral Superficial Angiomyxoma: A Case Report. J Maxillofac Oral Surg 15: 371-374.

12. Abarzua-Araya Alvaro, Aimillios Lallas, Simonetta Piana, Caterina Longo, Elvira Moscarella, et al. (2016) Superficial Angiomyxoma of the Skin. Dermatol Pract Concept 6: 47-49. 